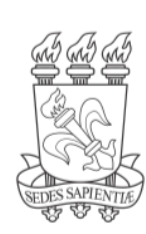

\title{
A irreversibilidade do tempo e o espírito de vingança: problemas para a proposta de um eterno retorno
}

\author{
The irreversibility of time and the spirit of revenge: problems for a \\ proposal of an eternal return
}

[...] O tempo andou riscando meu rosto Com uma navalha fina, sem raiva nem rancor

O tempo riscou meu rosto com calma.

Eu parei de lutar contra o tempo:

Ando exercendo instante

Eu acho que ganhei presença [...]

\section{Barbara Smolniakof ${ }^{1}$ (D)}

(Viviane Mosé)

' Universidade Federal de Santa Catarina, Florianópolis, SC, Brasil

\begin{abstract}
RESUMO
Este artigo discute a problemática que serve como ponto de partida para trazer à tona o eterno retorno em Assim Falou Zaratustra. Ele se constitui de dois tópicos, cada um apresentando uma parte do problema que Nietzsche via na noção linear de tempo e que o justifica propor uma perspectiva alternativa de tempo que leva em consideração a relação entre o próprio homem e o fenômeno da temporalidade, reconhecendo-a como a condição de possibilidade para a criação de valores e, consequentemente, a afirmação da vontade através desta criação.
\end{abstract}

Palavras-chave: Temporalidade; Vontade de Poder; Irreversibilidade; Eterno Retorno

\begin{abstract}
This article discusses the problem as a starting point to bring out the eternal return in Thus Spoke Zarathustra. It consists of two topics, each presenting a part of the problem that Nietzsche saw in the linear notion of time and which justifies him to propose an alternative perspective of time that takes into account the relationship that man himself establishes with the phenomenon of temporality, recognizing it as the condition of possibility for the creation of values and, consequently, affirmation of the will through this creation.
\end{abstract}

Keywords: Temporality; Will to Power; Irreversibility; Eternal Return 


\section{INTRODUÇÃO}

Este trabalho apresenta o problema que leva Nietzsche a propor o eterno retorno como uma nova forma de valorar o tempo, que tem como fio condutor a efetivação e afirmação da vontade. Nesse sentido, não pretendemos aqui esgotar o tema do eterno retorno, mas sim apenas apresentar o que pensamos ser o pontapé inicial que levou Nietzsche a propô-lo. Vale lembrar que o filósofo não apresentou um compromisso propriamente científico com a noção de tempo, ou seja, sua pretensão ao falar do tempo não era dizer se ele existe, o que é e como se desenvolve de fato. Porém, há em seu pensamento uma problematização de caráter existencial do fenômeno da temporalidade, na medida em que ele é pensado em relação à vida, mais especificamente a do homem. Em seu livro Assim Falou Zaratustra(1883-85), Nietzsche utiliza o termo "vida" no mesmo sentido em que usa "vontade de poder", na medida em que tal vontade se manifesta em tudo o que é vivo ${ }^{1}$.

A partir de um problema identificado na concepção linear de tempo, que emerge com a ascensão do cristianismo, Nietzsche propõe um novo modo de considerar a temporalidade, de maneira tal que ela esteja em consonância com a efetivação da vontade no mundo. É a partir da seção Da redenção do texto Assim falou Zaratustra que será dado o problema da linearidade do tempo na medida em que ele é pensado a partir do conceito de vontade de poder.

\footnotetext{
${ }^{1}$ Considerando o caráter dinâmico que Nietzsche atribui ao mundo, isto é, um conjunto de forças agindo e reagindo entre si que procuram se sobrepor e se superar, pode-se dizer que a vida é fundamentalmente luta. Em outros escritos, ao ser relacionada à noção de "valor" - enquanto uma apreciação humana criada a respeito do que o cerca - a vida é também critério de avaliação desses valores instituídos Cf. MARTON, 2016b, p. 21. Sobre a discussão a respeito da tradução mais adequada do termo Wille zur Macht, cf. Müller-Lauter, 1997, apresentação, nota de rodapé de número 2, onde Scarlett Marton explica o porquê de traduzir o termo como "vontade de potência". Segundo ela, se traduzir o termo por "vontade de poder", corre-se o risco de tomar o vocábulo "poder" em sentido político; contudo, traduzir por "vontade de potência" é também problemático porque pode conferir ao termo uma conotação aristotélica, embora pareça ser mais adequado entendendo o termo Wille como disposição, tendência e o termo Macht, associado ao verbo Machen, como fazer, produzir criar, efetuar. Não entraremos nessa discussão de qual tradução é melhor ou mais fiel ao pensamento nietzschiano, optamos pelo termo "vontade de poder" mais pela questão da tradução dos textos de Nietzsche usados, visto que em todos ele consta "poder".
}

Voluntas, Santa Maria, v.12, n.1, p. 01-16, jan/abril, 2021 


\section{O pressuposto da vontade de poder}

Em seu Assim falou Zaratustra, Nietzsche assume a noção de "vontade de poder", caracterizada como o elemento presente em tudo o que é vivo, como ponto de partida para sua problematização:

[...] “Onde há vida, também há vontade: mas não vontade de vida, senão - é o que te ensino - vontade de poder!

Muitas coisas o ser vivo avalia mais alto do que a própria vida; mas, através mesmo da avaliação, o que fala é - a vontade de poder!"2

Ao apresentar esta vontade como característica do que vive, Zaratustra identifica vida a vontade de poder. O querer da vontade, que é querer algo (isto é, mais poder), parte do princípio de superação de si a partir da busca por mais possibilidades de se manter vivo por meio da conservação e expansão. Nesse sentido, a vontade de poder não é algo apenas humano, mas está presente em todo ser orgânico; grosso modo, é o que mantém e fortalece a vida. Diante disso, pode-se dizer que até os elementos mais microscópicos presentes nos organismos são levados a se superar, no sentido de crescer e dominar - as células, tecidos, órgãos, têm impresso o caráter dinâmico de querer crescer, alcançar mais poder. Na medida em que o mundo é constituído por forças em conflito, elas se mostram como obstáculo umas às outras e procuram se superar a fim de se sobressaírem e estabelecer uma ordem hierárquica de obediência entre elas.

Talvez seja nesse sentido que Zaratustra, ao se perguntar em Do superar a si mesmo pelo modo de todo ser vivente, afirmará que onde quer que ele encontrasse vida, ouvia falar também em obediência ${ }^{3}$. A relação da vontade de poder se resume assim a crescimento e domínio para mais crescimento, bem como a superação da condição atual de si mesmo na medida em que se cresce.

\footnotetext{
2 NIETZSCHE, Assim Falou Zaratustra, 128.

${ }^{3}$ Cf. NIETZSCHE, Assim Falou Zaratustra, 127.
}

Voluntas, Santa Maria, v.12, n.1, p. 01-16, jan/abril, 2021 
Em tal cenário orgânico, o homem é também vontade de poder, contudo, a diferença é que ele é fundamentalmente um animal que cria valores4. Estes valores são o ponto de vista que o homem tem das coisas e a partir do qual ele dá um sentido a elas. Para Nietzsche, os valores não têm caráter absoluto, foram criados num determinado momento da história e em determinadas circunstâncias por alguma necessidade humana. Nesse sentido, valorar é o modo humano de se conservar e expandir: é valorando as coisas que o homem justifica e procura dar sentido à noz da sua existência. E é precisamente a vontade de poder que cria estes valores a partir dos quais o homem viverá, por isso tais noções estão tão fortemente relacionadas.

A partir da elucidação dos parágrafos acima dados a respeito do processo de forças que se constituem e procuram se sobrepor umas às outras culminando numa relação hierárquica de ordem e obediência - que ilustra a maximização da força e, portanto, a vontade de poder que resulta desta relação - pode-se dizer que vontade de poder é fundamentalmente comando. Nesse sentido, ela se encontra onde há justamente esta relação entre forças, seja a nível microscópico (nas células e órgãos que compõem um único corpo) seja a nível macroscópico (num organismo composto de diversos corpos, como a sociedade por exemplo).

Ressalte-se, desse modo, que a vontade de poder não se caracteriza como uma substância. Nietzsche não tinha a pretensão de fundar uma metafísica a partir de tal expressão, pois vontade enquanto aspecto do que é vivo não pode estar fora dos próprios organismos vivos, que, a rigor, manifestam-se enquanto luta e superação de obstáculos. Trata-se assim de um processo dinâmico que aparece no mundo. A vontade à qual Nietzsche se refere é querer-algo, ou seja, há sempre um conteúdo desta vontade, isto é, o próprio comando das forças: a maximização das forças que, na medida em que superam e comandam as mais fracas, atingem seu mais alto grau de poder 5 .

\footnotetext{
${ }^{4}$ Cf. NIETZSCHE, Assim Falou Zaratustra, 75.

${ }^{5}$ Ver nesse sentido STAMBAUGH, The Problem of Time in Nietzsche, 99-103; MARTON, O eterno retorno, 21-22 e NIETZSCHE, Ecce homo, § 668 e § 689 e STEGMAIER, Antidoutrinas, 36-37. Para mais
} 
Na medida em que a vontade de poder cria os valores, estes mesmos valores são incorporados a fim de não somente conservar a vida, mas antes fortalecê-la, maximizála em seu mais alto grau. Assim, enquanto a vontade de poder é a criadora dos valores que orientarão a vida, esta serve de critério de valor para estes valores criados pela vontade de poder: quanto estes valores contribuem para o crescimento da vida? Nesse sentido, os valores são criados em função da vida e o próprio valor destes valores são determinados a partir dela própria. Um valor é sinal de uma vontade criadora forte quando beneficia a vida, ao passo que um valor é criação de uma vontade fraca quando prejudica a própria vida6

Ao propor que os valores são criações do homem e utilizadas para a conservação e crescimento da vida, Nietzsche está a criticar e rejeitar o caráter universal, transcendente e imperecível atribuído às apreciações de bem e mal, os quais não deixam de ser apenas expressões da vontade de poder do homem que as criou. Para ele, tais valores perdem seu sentido a partir do momento em que se os retira dessa relação entre valoração, avaliação e vida. A partir disso, vemos que o que caracteriza a vontade de poder do homem é sua capacidade criativa.

Avaliar, enquanto a atividade humana por excelência, é uma criação e, segundo Zaratustra em Nas ilhas bem-aventuradas, criar é o que torna a vida mais leve, pois é através dela que o homem procura justificar sua existência e todo o sofrimento presente nela: "O querer liberta: é esta a verdadeira doutrina da vontade e liberdade"7 Contudo, esta capacidade humana criadora vê seu maior obstáculo no tempo, mais precisamente, na concepção que vigorou no Ocidente de tempo enquanto linearidade.

elucidações especificamente sobre o conceito de vontade de poder sugerimos a leitura de BRAZIL, Considerações acerca do conceito de Vontade de Poder, 67-84.

${ }^{6}$ Cf. fragmento póstumo de outono de 1887 caderno W II 19 [39], onde ele afirma que "os valores e suas mudanças são proporcionais ao crescimento e ao aumento do poder de quem estabelece os valores" (ênfase do autor). NIETZSCHE, Fragmentos Póstumos. Volumen IV, 243.

${ }^{7}$ NIETZSCHE, Assim Falou Zaratustra, 101.

Voluntas, Santa Maria, v.12, n.1, p. 01-16, jan/abril, 2021 


\section{A Irreversibilidade do Tempo}

É a partir do advento do Cristianismo, quando o acontecimento do mundo passa a ser compreendido em termos de criação, pecado original, redenção e parusia, que a concepção de tempo linear se impõe, assim, o mundo passaria a ter um começo no passado (criação) e um final no futuro. Isso resume o tempo a um conjunto de momentos pontuais necessariamente encadeados que desembocariam num télos, de modo que todos os instantes presentes desse conjunto não teriam um valor e um significado em si mesmos, mas dependeriam dos instantes que o sucedem ${ }^{8}$.

Este aspecto acarretaria a desvalorização da própria vida na medida em que ela é vivida no instante, pois com a desvalorização do momento presente, o sentido e o valor da vida seriam negados ou projetados a um além ou um aquém do presente, o qual nunca é realizado por si, mas com vistas a um futuro. Ademais, à medida que se concebe um ser superior que cria o mundo (e o próprio homem), confere-se a ele o caráter de eternidade, à qual se opõe a finitude e a temporalidade impostas ao homem enquanto criatura. É a partir dessa concepção cristã, portanto, que surge a antinomia entre temporalidade e eternidade ${ }^{9}$, na qual a última ganha primazia sobre a primeira.

O problema dessa concepção cristã de mundo é que, a partir da dicotomia eternidade-temporalidade, é conferida a esta suposta eternidade (representada por um deus transcendente) maior dignidade ontológica e a própria temporalidade do mundo e do homem é desvalorizada. Frente a esta desvalorização do transitório em nome do eterno o homem perde o valor da existência que se efetiva na própria temporalidade. Nietzsche propõe precisamente o contrário, isto é, a valorização da transitoriedade em detrimento desta suposta eternidade.

Segundo ele, a criação humana só é possível no tempo, pois o homem se localiza no tempo e os próprios valores são temporais e circunstanciais. Nesse sentido, a existência de um Deus (tal como postulado pelo cristianismo por exemplo) ou até

\footnotetext{
${ }^{8}$ Cf. MECA, Nietzsche ou a eternidade do tempo, 187-188.

${ }^{9}$ Cf. STAMBAUGH, The Problem of Time in Nietzsche, 14-15.
} 
mesmo de valores eternos vai contra a própria vontade de poder como criadora de valores ${ }^{10}$. Portanto, a eternidade, tal como concebida pelo cristianismo, é criticada por Nietzsche em nome da vida. Além disso, a transitoriedade é exaltada e reconhecida como o solo mesmo da efetivação plena da vontade de poder, pois seu próprio caráter criativo exige a temporalidade.

Com a negação da suposta eternidade forjada pelo cristianismo, Nietzsche está a negar também a própria acepção de linearidade pensada pela vertente religiosa. Isso traz como consequência o repúdio à noção de télos. Pois pensada como um encadeamento de momentos pontuais que teriam um fim no futuro, a concepção linear de tempo impõe ao mundo a característica de finalidade que seria alcançada ao atingir o fim do processo. No lugar dessa linearidade e sua finalidade a ser atingida, Nietzsche proporá um eterno retorno de todos os momentos já vividos a partir da combinação entre um tempo eterno e forças finitas, o que acarretaria a limitação das combinações possíveis entre as forças e a repetição destas no tempo que é eterno.

Nesse sentido, a partir desta concepção, Nietzsche nega a interpretação teleológica de que há um fim a ser atingido; segundo ele não há uma finalidade a ser alcançada, mas tão somente as forças que se manifestam e se esvaem no curso da temporalidade ${ }^{11}$. Contudo, ainda que a temporalidade seja reconhecida, é nela mesma que o homem encontra seu maior obstáculo para alcançar sua mais alta forma de afirmação. No capítulo Da Redenção da segunda parte de Zaratustra, ele nos diz:

Vontade - é este o nome do libertador e trazedor de alegria: assim vos ensinei, meus amigos! Mas, agora, aprendei também isto: a própria vontade ainda se acha em cativeiro.

O querer liberta: mas como se chama aquilo que mantém em cadeias também o libertador?

"Foi assim!": é este o nome do ranger de dentes e da mais solitária angústia da vontade. Impotente contra o que está feito - é ela um mau espectador de todo o passado.

\footnotetext{
${ }^{10}$ Cf. NIETZSCHE, Assim Falou Zaratustra, 99-101.

${ }^{11}$ Cf. MARTON, 0 eterno retorno, 43-44. Para mais elucidações a respeito da cosmovisão nietzschiana, consultar MARTON, Extravagãncias, 65.
}

Voluntas, Santa Maria, v.12, n.1, p. 01-16, jan/abril, 2021 
Não pode a vontade querer para trás; não poder partir o tempo e o desejo do tempo - é esta a mais solitária angústia da vontade ${ }^{12}$.

Eis o problema: por um lado, a vontade humana é libertadora, porque ela cria valores que possibilitam o homem dar sentido à sua existência. Em contrapartida, ela parece ser também prisioneira do tempo, uma vez que nada pode frente à prisão do tempo passado e seu caráter criativo se torna impotente. Ao reconhecer a temporalidade, a vontade está a assumir o aspecto mais característico dessa temporalidade: a irreversibilidade, isto é, a propriedade necessária de seguir sempre para frente e que impossibilita regressar a estágios anteriores. Enquanto linha reta, que leva a uma única direção (futuro), o tempo instituiria o passado como a maior angústia para a vontade, que perde, frente a ele, seu caráter criador e que, sob esse ângulo, restringir-se-ia a exclamar resignadamente "Foi assim" e reconhecer o passado como um mero fato levado a termo.

A partir deste sentimento de angústia de nada poder, o homem procura meios de se refugiar da aflição da irreversibilidade. É possível, assim, vislumbrar dois aspectos da vontade de poder do homem, a saber: (i) o aspecto criador de valores e (ii) o aspecto vingativo, da reação à angústia que deriva da sua relação com o tempo ${ }^{13}$. Ambas as características da vontade permitem ao homem encontrar um modo de fugir de sua prisão denominada "Foi assim", porém, de distintas maneiras.

\section{O espírito de Vingança}

A característica vingativa da vontade é aquilo que estabelece uma relação problemática com o tempo e se caracteriza como o que Nietzsche denomina espírito de vingança, que pode ser entendido como a "aversão da vontade pelo tempo e seu 'Foi assim!"'14. A partir da constatação de sua impotência frente ao passado, a vontade de

\footnotetext{
12 NIETZSCHE, Assim Falou Zaratustra, 151. Ênfase nossa.

${ }^{13}$ Cf. BRUSOTTI, O eterno retorno em Assim falou Zaratustra, 156-158; VATTIMO, Diálogos com Nietzsche, 31-33.

${ }^{14}$ NIETZSCHE, Assim Falou Zaratustra, 151.
} 
poder do homem se resigna, deixa de lado sua capacidade criadora e toda forma de justificar a angústia produzida pela irreversibilidade, torna-se um mau espectador de todo o passado. Dito por Zaratustra, o espírito de vingança - "foi esta até agora, meus amigos, a melhor reflexão dos homens: e que onde havia sofrimento deveria sempre haver castigo"15. É o espírito de vingança que se restringe a exclamar "Foi assim". Quando muito, limita-se a forjar noções como "pecado", "sacrifício", "castigo" e "culpa" para conferir à vida um caráter negativo, projetar para um futuro ou uma instância transcendente a esperança de se redimir desta angústia que resume a própria vida.

O espírito (ou vontade) de vingança poderia ser colocado como o contra princípio à noção nietzschiana de amor fati. Segundo Brusotti, a vontade presa ao tempo destaca seu caráter negativo e obscurece seu aspecto positivo, ao passo que o amor fati é exatamente o contrário: é a partir deste princípio que se aprende a amar a vida como um todo ${ }^{16}$. Diferentemente do amor fati, que procura aprender um modo de afirmar a temporalidade e, consequentemente, a vida, o espírito de vingança foge de toda e qualquer justificativa. Nem mesmo as noções de "prêmio" ou "castigo" forjadas por ela contam como justificativas; antes parecem mais um modo de perpetuar a aversão contra a irreversibilidade e evitar o reconhecimento da temporalidade como intrínseca à vida.

Vê-se que esse tipo de comportamento vingativo contra a vida em sua temporalidade é típico do que a religião cristã denomina "redenção", que, ao priorizar a eternidade fictícia, vê na existência o castigo e na "vida após a morte" o prêmio pelo sofrimento corpóreo. Contudo, segundo o filósofo, esse tipo de redenção é insuficiente,

\footnotetext{
15 NIETZSCHE, Assim Falou Zaratustra, 151. Ênfase nossa.

${ }^{16}$ A expressão amor fati deriva do latim e pode ser entendida como amor ao destino. Nietzsche o utiliza para se referir à aprendizagem de amar o que é necessário. São poucas as vezes que ele menciona esta expressão em suas obras (Cf. por exemplo A Gaia Ciência § 276; Ecce homo, "Porque sou um destino" §10) e em sua filosofia madura ela está estreitamente relacionada à doutrina do eterno retorno. Poder-se-ia dizer que o amor fati, enquanto o princípio que nos diz para amarmos o necessário (e isso envolve o próprio sofrimento), é o critério exigido para a afirmação do eterno retorno e, consequentemente, da vida. Mas não nos deteremos a ele neste momento, por isso, recomendamos a conferência de outros textos que tratam do assunto, SMOLNIAKOF, Amor fati como condição necessária para a afirmação do eterno retorno, 145-155; RUBIRA, 0 amor fati em Nietzsche, 227-236.
} 
pois ao renegar o tempo não se estaria resolvendo o problema de sua irreversibilidade - a vontade ainda permaneceria presa às amarras do passado como sua maior angústia. Mais até: alimentar-se-ia inclusive uma aversão à própria existência, uma vez que ela se encontra neste tempo que é renegado.

Em lugar dessa redenção cristã que condena a vida e o tempo, Nietzsche propõe uma redenção afastada deste contexto religioso de expiação dos pecados mediante a graça de um ser superior. Para ele, o único modo legítimo de se redimir com o tempo seria valorá-lo de maneira diferente, sem Ihe atribuir nenhuma irreversibilidade que constranja a vontade, mas assumi-lo como o próprio objeto da vontade. Nas palavras do filósofo: "redimir os passados e transformar todo 'Foi assim' num 'Assim eu o quis!' somente a isto eu chamaria redenção!"177. Ou seja, interpretar a temporalidade enquanto parte constituinte do vir-a-ser do mundo, no qual é possível a atuação e criação da vontade de poder do homem, de modo que ele afirme sua criação e a queira incondicionalmente.

Assim, a redenção não exigiria apenas um novo modo de interpretar o tempo, mas antes a própria reconciliação do tempo com a vontade, a partir do reconhecimento de seu caráter ativo, de maneira tal que ela não o rejeite e o assuma como seu âmbito de criação e efetivação ${ }^{18}$. Trata-se, assim, de emitir um juízo de valor que esteja em consonância com a própria vontade, a partir do qual não se exclamaria mais "Foi assim", mas "Assim eu o quis". Qualquer outro modo de uma possível redenção, que não leve em consideração a afirmação da temporalidade como objeto da vontade, não passa de mero escapismo. O que o filósofo propõe é perceber que a mera reação pacífica frente ao passado por parte da vontade ao dizer "Foi assim" é um mero "fragmento"19, pois

\footnotetext{
17 NIETZSCHE, Assim Falou Zaratustra, 151. Ênfase nossa. Nesse sentido, redimir a temporalidade seria mais precisamente interpretá-la a partir do critério da vontade, assumir o querer como o fio condutor da relação entre o homem e o tempo, cf. também VATTIMO, Diálogos com Nietzsche, 45-47.

${ }^{18}$ Cf. VATTIMO, Diálogo com Nietzsche, 40-47. Vattimo afirma em certo momento que a redenção necessária para deixar de ver o passado como um grilhão da vontade exige "um abandono da representação habitual das relações entre vontade humana, tempo e mundo".

${ }^{19}$ Cf. NIETZSCHE, Assim Falou Zaratustra, 152.
}

Voluntas, Santa Maria, v.12, n.1, p. 01-16, jan/abril, 2021 
não ilustra o caráter total da vontade como criadora, mas apenas a constatação do destino se consumando.

Sendo criadora, a vontade pode se impor frente a este fato e transformá-lo a seu propósito dizendo: "Mas assim eu quis". Ao estabelecer o tempo como seu objeto, a vontade se torna sua própria redentora, está a assumir a irreversibilidade do tempo e a superar o espírito de vingança, dando mais um passo em direção à afirmação plena da existência. Contudo, a pergunta que o próprio Zaratustra coloca é: "alguma coisa mais elevada do que toda a reconciliação deve querer a vontade que é vontade de poder; mas como chega lá? Quem Ihe ensinará também o querer pra trás?"20.

Zaratustra vê que a solução para a superação do espírito de vingança seria reconhecer o tempo como parte do que a vontade quer; e, na medida em que o passado é parte constituinte do tempo, este passado também precisa ser reconhecido pela vontade do homem. A questão que permanece é: como fazê-lo, como aprender a querer para trás e dizer "assim eu quis"? É com esta questão que Zaratustra encerra a seção $D a$ redenção, à qual ele responderá posteriormente com o anúncio do eterno retorno do mesmo como a forma de não só querer para trás, mas de querer um número infinito de vezes. É a partir do eterno retorno que o filósofo se depara, então, com uma possível redenção do problema tempo-vontade, pelo menos num primeiro momento ${ }^{21}$. Pois a partir do eterno retorno como uma hipótese cíclica do tempo seria possível superar a irreversibilidade, uma vez que a vontade passaria a poder sobre todas as suas instâncias, na medida em que se reconciliariam os momentos pontuais passadopresente-futuro num único instante.

Esta proposta de um tempo cíclico não teria um caráter científico, porque Nietzsche não parece estar preocupado com a verdade a respeito dela, o que importa seria mais a relação que o homem teria com o tempo (e com a vida, na medida em que

\footnotetext{
${ }^{20}$ NIETZSCHE, Assim Falou Zaratustra, 152. Ênfase nossa.

${ }^{21}$ Sobre o tempo como problema ao qual Nietzsche se propunha resolver com a formulação do eterno retorno, Cf. VATTIMO, Diálogo com Nietzsche, 11. Vattimo enfatiza que a concepção de tempo proposta por Nietzsche não tem um sentido gnosiológico ou metafísico, mas mais propriamente existencial, isto é, o tempo é pensado a partir da existência humana e sua relação com o mundo.
} 
esta está no tempo) na hipótese dele se desenvolver como um ciclo. Isso pode ser lido no Zaratustra em Da visão e do enigma e em A Gaia Ciência, aforismo 341, onde Nietzsche lança a hipótese do retorno e pergunta pela reação do homem frente a ela: se ele rangeria os dentes ou bendiria aquele que trouxesse essa notícia. Além disso, ainda sugere que para o homem afirmar a possibilidade de que o tempo é cíclico ele teria de ter uma relação diferente com a própria vida, teria de estar de bem consigo mesmo, o que parece ser uma menção ao amor fati22. Por isso, esta concepção do eterno retorno teria um caráter propriamente existencial, uma vez que salienta a relação do homem com sua própria vida e a existência como um todo.

Contudo, é possível que o próprio eterno retorno seja um problema: ele pode se apresentar como o maior dos desafios a Zaratustra, pois ao abolir a irreversibilidade e a teleologia cristãs, assume-se a própria ausência de objetivo da existência; com a desvalorização da concepção cristã de tempo que guia a existência humana, desvaloriza-se a própria existência tal como ela estava sendo interpretada à luz do cristianismo. É no livro A Gaia Ciência, no aforismo 341, que Nietzsche anuncia de modo hipotético o eterno retorno através da boca de um demônio. Ele nos apresenta a possibilidade da repetição de todas as coisas ("cada suspiro e pensamento, o que há de menor e maior") num movimento circular ("na mesma ordem e sequência") e, ao final de sua exposição, põe-nos a questão sobre qual seria nossa reação a esse demônio que assim nos falasse:

“[...] A perene ampulheta do existir será sempre virada novamente - e você com ela, partícula de poeira!" Você não se prostraria e rangeria os dentes e amaldiçoaria o demônio que assim falou? Ou você já experimentou um instante imenso, no qual the responderia: "Você é um deus e jamais ouvi coisa tão divina!"23.

A partir da exposição do retorno de todas as coisas, apresentam-se duas possíveis reações à doutrina, que, em última instância, ilustram dois tipos de vida ou, mais precisamente, dois tipos de homem. Aquele que amaldiçoasse o demônio o faria

\footnotetext{
${ }^{22}$ Cf. NIETZSCHE, A Gaia Ciência, 205.

${ }^{23}$ NIETZSCHE, A Gaia Ciência, 205.
}

Voluntas, Santa Maria, v.12, n.1, p. 01-16, jan/abril, 2021 
porque a possibilidade do retorno de sua própria vida lhe pareceria insuportável: este tipo de homem incapaz de afirmar o retorno da existência tem, portanto, um caráter fraco. Em contrapartida, aquele que o bendissesse, que já tivesse passado por um instante imenso a ponto de bendizer a notícia do retorno, o faria devido seu caráter afirmador da existência.

Vê-se que estas duas possíveis reações que o homem poderia ter à novidade ilustram o pensamento do retorno tal como Nietzsche os exprimiu em seu livro Ecce homo (1889) e em alguns fragmentos póstumos encontrados na compilação intitulada A Vontade de Poder (1901). No capítulo dedicado ao Assim Falou Zaratustra de Ecce homo, Nietzsche apresenta o eterno retorno como "a mais elevada forma de afirmação que se pode em absoluto alcançar"24. Em contrapartida, em um fragmento póstumo de 1886-87, ele propõe radicalizar este pensamento e pensá-lo em sua forma mais terrível: "a existência, tal como é, sem fim nem objetivo, mas inevitavelmente retornando, sem um finale no nada: 'o eterno retorno'. Essa é a forma mais extrema do niilismo: o nada (o 'sem sentido') eterno!"25.

Em outras palavras, o sentido do eterno retorno parece ser ambíguo. Por um lado, ele é apresentado como uma fórmula de afirmação: aquele que quer o retorno eterno de sua vida, com tudo que há de maior e menor nela, está afirmando incondicionalmente sua existência, está dizendo sim à própria vida como sua possibilidade de criação autêntica de valores e vivência a partir de sua criação. Por outro lado, o mesmo pensamento surge como a própria radicalização do niilismo, como a mais extrema forma de assumir o mundo destituído de objetivo e valor próprios, como um pensamento que pode transformar e derrubar o homem ${ }^{26}$. Ora, a partir disso, nota-se que mais que a saída de um problema, o eterno retorno se apresenta como a abertura para outro problema, a saber, o niilismo passivo, o qual, dada a dimensão do

\footnotetext{
24 NIETZSCHE, Ecce Homo, 79.

${ }^{25}$ NIETZSCHE, FP verão de 1886 - outono de 1887, Caderno N VII 3, 5[71], 2006, 165.

${ }^{26}$ Sobre o caráter dúbio do eterno retorno relativo à perspectiva do homem que se depara com ele, cf. STEGMAIER, Antidoutrinas, 42.
}

Voluntas, Santa Maria, v.12, n.1, p. 01-16, jan/abril, 2021 
problema, merece um trabalho dedicado exclusivamente a ele ${ }^{27}$. A questão que se pode assumir como ponto de partida é: como diferenciar o eterno retorno enquanto um modo negativo de reagir à existência (vendo-a como sem sentido) do eterno retorno como um pensamento de caráter afirmador frente a ela?

\section{CONSIDERAÇÕES FINAIS}

Este trabalho se deteve ao que parecem ser os passos iniciais para Nietzsche propor o eterno retorno como uma perspectiva alternativa sobre o fenômeno da temporalidade. Sua proposta de um tempo cíclico surge como uma tentativa de superação da linearidade imposta pela tradição metafísica-cristã, pois ele identificara problemas nela justamente quando pensada em relação com a efetivação da vontade do homem no mundo. Dado que o tempo linear anda sempre para a frente e não abre a possibilidade de a vontade agir para trás, ele a torna vingativa, pois a impossibilita de exercer sua atividade mais característica: a criação. Apontados os dois aspectos do tempo linear como irreversível e como o responsável pelo aspecto vingativo da vontade do homem, o eterno retorno é sugerido como uma alternativa que valoriza o tempo em sua relação com o homem e possibilita sua atividade de criar valores. Apesar de não nos determos especificamente ao eterno retorno, já se pôde aqui fazer alusão a algumas de suas características. Ele é um modo de ver a temporalidade, não como liner, mas como um desenvolvimento cíclico dos instantes que o homem efetiva e que, portanto, podem retornar. Se por um lado ele parece eliminar o problema da irreversibilidade e da impotência da vontade frente a um momento que já passou, por outro, ele coloca o homem frente a outra questão que envolve sua existência que se realiza no tempo: estaria ele disposto a viver um número infinito de vezes aquilo que vive?

\footnotetext{
${ }^{27}$ Sobre o eterno retorno como o que pode desencadear o niilismo Cf. SMOLNIAKOF, Niilismo: conceito e ocorrência em Assim Falou Zaratustra, 39-58.
} 


\section{AGRADECIMENTOS}

Agradeço e dedico este texto ao meu querido Ozeias pelo apoio e também à minha melhor amiga Michele. Meus dois motivos para querer afirmar o eterno retorno.

\section{REFERÊNCIAS}

BRAZIL, L. G. Considerações acerca do conceito de Vontade Poder. GRIOT - Revista de Filosofia, Amargosa, Bahia, v.5, n.1, 67-84, 2012.

BRUSOTTI, M. O eterno retorno em Assim Falou Zaratustra. Estudos Nietzsche, v.3, n.2, 149167, 2012.

GALPARSORO, J. I. Sobre el supuesto carácter circular del tiempo en el eterno retorno de Nietzsche. Daímon. Revista Internacional de Filosofía, n. 57, 81-95, 2012.

MACHADO, R. Zaratustra. Tragédia nietzscheana. $3^{\text {a }}$ edição. Rio de Janeiro: Jorge Zahar Ed., 2001.

MARTON, S. Extravagâncias: ensaios sobre a filosofia de Nietzsche - $3^{\text {a }}$ ed. - São Paulo: Discurso Editorial e Editora Barcarolla, 2009.

MARTON, S. (editora responsável). Dicionário Nietzsche. São Paulo: Edições Loyola (Sendas \& Veredas), 2016a.

MARTON, S. O eterno retorno, "a concepção básica de Zaratustra". Cadernos Nietzsche, Guarulhos/Porto Seguro, v.37, n.2, 2016b.

MECA, D. S. Nietzsche ou a eternidade do tempo. Cadernos Nietzsche, São Paulo, n.33, 181 196, 2013.

NIETZSCHE, F. W. A Gaia Ciência. Tradução Paulo César de Souza. São Paulo: Companhias das Letras, 2012.

NIETZSCHE, F. W. Assim Falou Zaratustra: Um livro para todos e para ninguém. Tradução de Mário da Silva. 9a edição. Rio de Janeiro: Bertrand Brasil, 1998.

NIETZSCHE, F. W. Ecce homo: como alguém se torna o que é. Tradução, notas e posfácio Paulo César de Souza. São Paulo: Companhia das Letras, 2008.

NIETZSCHE, F. W. Fragmentos Póstumos. Volumen IV (1885-1889). Madrid: Editorial Tecnos, 2006. 
ORELLANA, R.C. Lo que imagina el querer: tiempo y resentimiento en Nietzsche. HYBRIS. Revista de Filosofía, Vol. 6, n² 2, 53-64, 2015.

RUBIRA, L. O amor fati em Nietzsche: condição necessária para a transvaloração? Polymatheia, Fortaleza, v.4, n.6, 227-236, 2008.

SMOLNIAKOF, B. Amor fati como condição necessária para a afirmação do eterno retorno. Polymatheia, Fortaleza, v. 13, n. 23, 145-155, 2020.

SMOLNIAKOF, B. Niilismo: conceito e ocorrência em Assim Falou Zaratustra. Occursus: Revista de Filosofia. Fortaleza, v.5, n.2, jul/dez. 2020, 39-58.

STAMBAUGH, J. The Problem of Time in Nietzsche. Translated by John F. Humphrey, Bucknell University Press. London and Toronto: Associated University Press, 1987.

STEGMAIER, W. Antidoutrinas. Cena e doutrina em Assim Falou Zaratustra de Nietzsche. Cadernos Nietzsche, 25, p. 11-47, 2009.

VATTIMO, G. O niilismo e o problema da temporalidade. In: VATTIMO, G. Diálogo com Nietzsche. Ensaios 1961-2000. Tradução Silvana Cobucci Leite. São Paulo: Editora WMF Martins Fontes, 2010.

\section{Contribuição de autoria}

\section{1 - Bárbara Smolniakofa}

Mestranda em Filosofia

https://orcid.org/0000-0002-4998-144X•barbarasmolniakof@gmail.com

Contribuição: Único autor

\section{Como citar este artigo}

SMOLNIAKOFA, Bárbara. A irreversibilidade do tempo e o espírito de vingança: problemas para a proposta de um eterno retorno. Voluntas Revista Internacional de Filosofia, Santa Maria, v. 12, n. 1, e9, 2021. DOI 10.5902/2179378664177. Disponível em: https://doi.org/10.5902/2179378664177. Acesso em: dia mês abreviado. ano. 